\title{
El deterioro medioambiental de una zona de montaña como consecuencia de su actividad turística: el caso de la Sierra de Guadarrama
}

\author{
M. ${ }^{a}$ Pilar González Yancl
}

\begin{abstract}
RESUMEN
La proximidad a una zona densamente

poblada, como es Madrid y su Area Metropolitana, de una pequeña cadena montañosa de notables atractivos naturales y culturales contribuye a aumentar y acelerar el proceso de degradación del frágil ecosistema de montaña. El constante aumento de la edificación en la zona, acompañado de infraestructuras de todo tipo, el afán de promoción turistica y la masiva arluencia de visitantes, especialmente concentrados en las fechas festivas $y$ de vacaciones, suponen el más grave peligro para un espacio seriamente amenazado en su supervivencia.
\end{abstract}

ABSTRACT

The situation of a small mountainous range of notable attractive features, natural and cultural, located near a highly populated zone as it is Madrid and its metropolian area, contributes to increase and accelerate the degradation process of the fragile mountainous ecosystem. The constant rise of building in the area, along with all kinds of infrastructures, the wish for tourist promotion and the massive influx of visitors, especially in festivities and holidays, are the most serious risk for a space whose survival is endangered.

\section{INTRODUCCIÓN}

Madrid es una de las pocas grandes ciudades del mundo que dispone a poca distancia de una zona montañosa de interés. Ciertamente se trata de una cadena discreta, con cimas que no llegan a los $2.500 \mathrm{~m}$. de altitud y que se levanta sobre una meseta de por sí bastante elevada, además de que ocupa una superficie reducida. No obstante, desde el punto de vista 
medioambiental y geográfico presenta una gran riqueza. Posee una notable vida animal, así como tesoros geomorfológicos, tal como la Pedriza del Manzanares y restos de la última glaciación, un magnífico bosque de pino silvestre de los más meridionales de Europa y parajes de notable belleza, preciosos arroyos, vistosas cimas y domos graníticos. También desde el punto de vista humano es muy destacable: pequeños pueblos de gran encanto y magníficas obras arquitectónicas, como el monasterio de El Escorial, palacios y conjuntos urbanísticos como Riofrío, La Granja $e$, incluso, restos romanos de gran valor.

Precisamente por todo lo antedicho es hoy una Sierra que muchos consideramos seriamente amenazada desde muchos frentes. Esta amenaza le viene causada, sobre todo, por dos cosas: su belleza y notable atractivo y la proximidad a la gran ciudad, en un momento, considerado globalmente, de desarrollo y pujanza económica, en que estamos inmersos.

\section{CAUSAS DE LA AMENAZA}

Vamos a analizar, en primer lugar algunos aspectos que afectan a este espacio de montaña y que se relacionan directamente con lo que hemos definido como causas de la amenaza. La proximidad de la gran ciudad, incrementada por la facilidad creciente de los medios de transporte $y$, de forma especial, por el uso del automóvil particular, hace que la Sierra se convierta en el objetivo primordial tanto para "expansión» de la propia ciudad, como para constituir su principal entorno de turismo. En una búsqueda de "calidad de vida", en la que una componente es la calidad paisajística, la Sierra es deseada para vivir en ella y no sólo como segunda residencia, sino como lugar de vivienda habitual, con el consiguiente incremento de la edificación y del tráfico.

Los ayuntamientos y los habitantes autóctonos abandonan los usos tradicionales y se terciarizan. Sin olvidar que la agricultura desde sus inicios ha constituído un agente destructor del medio ambiente natural, negativo para el equilibrio ecológico hay que tener en cuenta que el hombre en los usos tradicionales mantenía un cierto equilibrio con la naturaleza, por mero afán de supervivencia. Además, la pequeña actividad agraria en ámbitos como el de montaña, con pocos medios técnicos, ha llevado a cabo una destrucción muy lenta, basada, sobre todo, en el larguísimo período de tiempo en que se ha practicado. Ciertamente los agricultores para cultivar y crear pastos destruían la vegetación existente, removian suelos, etc. pero también "cuidaban" el territorio, recogían leña, limpiaban el bosque,etc. El abandono de los usos tradicionales va unido a la terciarización. 
ción. Hoy, la meta de los ayuntamientos está en el turismo y los servicios. Los puestos de trabajo para la población se crean fundamentalmente en la construcción, la restauración y el comercio relacionado con la actividad turística, lo que provoca una auténtica obsesión por atraer gentes (clientes). Así, no es extraño que se reflejen en la prensa comentarios de alcaldes y de empresarios de la zona que, ante un verano de temperaturas suaves, como el pasado de 1997, hablen de zona catastrófica por el retraimiento de visitantes. Se crea una espiral, el pueblo crece, necesita trabajo, prolifera la creación de empleos en la construcción y la restauración, que para mantenerse precisan que se atraiga a mucha clientela y que se siga edificando a costa de recalificar terrenos y surge la especulación, que ante nada se detiene.

Al tiempo se desarrolla una cultura medioambiental, que es muy loable y hace que la población se sienta atraída por la naturaleza y por el patrimonio cultural, en sentido amplio. Los «medios» estimulan a la población a acudir, en el caso que nos ocupa, a la Sierra, para descubrir sus bellezas, incluso las de los parajes más recónditos, que dejan de serlo. En tal información se pueden detectar intereses subyacentes, como cuando se informa de forma inexacta de la existencia de nieve abundante para esquiar. A veces se levantan voces de protesta si se augura mal tiempo, porque informar de ello puede retraer a los visitantes (el pasado verano hubo cartas en este sentido en diarios madrileños). Los organismos oficiales, en un afán encomiable de conservación del medio natural, establecen medidas de protección. No obstante su utilidad, en ocasiones, una vez la zona es declarada como protegida, se llevan a cabo en ella actividades que provocan una gran afluencia de personas. Por otro lado, se crean organismos concretos con la finalidad de "promocionar» la zona (por ej. Deporte y Morntaña en la Sierra), que intentan multiplicar la oferta de actividades con una voluntad de "educar" en la cultura medioambiental, pero con consecuencias diversas, no siempre beneficiosas para la naturaleza y que, desde luego, atraen a gran número de personas. Como ejemplo se puede citar la instalación de cañones de nieve, apertura de nuevas zonas de esquí, organización de excursiones a pie, bicicleta, etc.

Todo lo que comentamos hace que la Sierra sea un espacio en auge, que atrae población estable y de paso y que se desarrolla, pero que podíamos decir «muere de éxito", pues este desarrollo conlleva su deterioro. Antes de analizar algunas consecuencias se pueden denunciar, a modo de ejemplo, algunos notables déficits, que afectan sobre todo a las áreas más elevadas, donde se dan usos turísticos, como estaciones de esquí, senderismo, etc. Hay males que vienen del pasado, como repoblaciones poco acertadas con especies no autóctonas y permisividad para edificar, pero 
ciñéndonos al presente podríamos destacar varias. El bosque no se limpia suficientemente. Ya no se ocupan los lugareños, como antaño y en muchas zonas prolifera la maleza, con el consiguiente peligro de incendios en época de sequía. Se detectan importantes problemas en la salud de la vegetación y se observan pocas medidas al respecto ¿qué ocurre con los rebollos cada año más enfermos de las partes bajas y con los pinos secos, algunos en su totalidad, que han proliferado en todo el pinar de Balsaín, especialmente desde el mes de agosto pasado? La madera de los árboles caídos tras la gran nevada de enero de 1996 se está sacando muy lentamente. Los aparcamientos no se limpian adecuadamente y las basuras se adueñan del suelo, no siendo raro ver a primera hora del domingo los contenedores ya rebosantes. No hay facilidad de evacuación en caso de incendio o catástrofe natural en zonas como La Pedriza. Existen, por otro lado, pistas y hasta carreteras que debieran ser, en todo caso para uso muy restringido que, al no estar cerradas, son utilizadas por vehículos particulares de personas que procuran llegar con su coche lo más arriba posible, en su pretendido amor a la naturaleza (por ejemplo la carretera de la Bola o la que llega a las instalaciones militares al pie de la pista del Escaparate). Hay en la Sierra buen número de edificaciones, incluso en alguna cumbre, como las instalaciones de Televisión Española en la Bola del Mundo, que desarrollan en su entorno verdaderos basureros, sin que se les exija mantener aquél como estaba antes de su llegada. Tampoco se repuebla el terreno deforestado para construcciones como el depósito de agua para surtir a los cañones de nieve en lo alto del Telégrafo y otros similares.

Indudablemente existe un decidido deseo de protección por parte de las autoridades, digno de toda alabanza y se toman algunas medidas importantes y positivas, como las que desde hace no muchos años prohibe practicar moto-cross, o acampar o encender fuego. Por otro lado se abren puestos de información para mostrar posibles excursiones, senderos, etc. y proliferan los libros, mapas, guías, etc. para "enseñar» la Sierra al visitante, con lo que se consigue un efecto positivo de "sensibilización" hacia los problemas y un efecto negativo de atracción de más población. Pese a la buena voluntad de las medidas citadas en la realidad hay escasa información de aspectos como las prohibiciones (se hacen mucho más patentes en otros países como Estados Unidos) y sobre todo hay un claro déficit de vigilancia, de modo que, pese a la prohibición no es difícil encontrar a unos motoristas que se adentran por la Senda de los Herreros, a grupos que acampan y hacen fuego donde está prohibido, etc. Casi nunca se ven forestales, en especial en la parte que administrativamente pertenece a la Comunidad de Madrid, siendo menor el problema en la vertiente segoviana. 
A menudo se tiene la sensación de que falta un proyecto claro, común y sólido de actuación en la Sierra y que las ideas cambian y se actúa a impulsos. Por ejemplo cuando hay un año seco y con poca nieve se pone en marcha un movimiento que exige actuar para potenciar recursos como la nieve artificial. En cambio, en un año frío y con mucha nieve, en que acude la gente de forma masiva, se pone en marcha el mecanismo de hacer ver que es desastroso el estado de las infraestructuras y que se deben construir más accesos y aparcamientos. Por otro lado se han construido aparcamientos, que en sí ya suponen una agresión y se permite que una parte de los mismos se dedique a actividades comerciales, con dudoso control sanitario, fomentando una nueva afluencia de clientes que encuentren "algo que hacer" una vez en el puerto. Muchos temas se toman y se abandonan de forma intermitente, dependiendo de los vientos que soplen, ante el sobresalto de asociaciones y movimientos ecologistas, que ven resucitar viejos temas de gran impacto medioambiental de llevarse a efecto (construcción de nuevos accesos, nuevos aparcamientos, telecabinas,etc.).

\section{ALGUNAS CONSECUENCIAS}

El resultado de todo lo anterior es que se detectan muchos problemas que, en buena parte por la gran afluencia de personas en un espacio reducido y frágil, y por la confluencia de intereses variados por conseguir "rentabilidad" de este espacio, conducen a su deterioro cada vez más acelerado. Como ejemplo podríamos citar que los caminos se van ensanchando hasta constituir verdaderas pistas, que la erosión se acelera, que la basura prolifera, incluso en las partes mas elevadas, que se genera una contaminación que cada vez afecta más a la vegetación, en la que tiene su parte el elevado tráfico de vehículos. Los aparcamientos y espacios edificados contribuyen al cambio en las condiciones medioambientales que propician cambios climáticos (la mayor emisión de calor provoca, lógicamente, una menor cantidad de nieve, por ej.). Con todo ello el espacio natural se reduce sin parar ante el avance de la edificación, carreteras, aparcamientos, infraestructuras de esquí,etc.

\section{CONCLUSIÓN}

La mayoría de los comentarios realizados no son exclusivos de la Sierra de Madrid. Pocos lugares excepcionales de la Tierra escapan hoy al 
acoso del turismo, entre otros males y de forma muy especial los espacios que han sido declarados como de especial protección. No obstante no se debe interpretar que nos oponemos a que se creen espacios protegidos, de un lado, o a que la población disfrute, aproveche y utilice los espacios naturales y entre ellos los de mayores riquezas paisajísticas, o de otro orden. Nada más lejos de nuestra intención. La protección es absolutamente necesaria y mucho nos alegra que cada vez más gente quiera acercarse a la naturaleza. Ahora bien, hay que tener clara conciencia de la realidad de lo que supone la masificación y de que la única esperanza de que nuestros hijos hereden algo de lo que nosotros hemos recibido es si somos capaces de algo que parece muy simple: poner grandes dosis de sentido común en nuestras acciones.

El sentido común en el caso que nos ocupa de la Sierra de Madrid pasa por que, a nivel individual, de usuarios, reflexionemos sobre lo que supone ir con una bicicleta de montaña por pequeñas sendas (no una persona, sino cientos), e incluso lo que supone acercarse a la montaña, para lo que es precisa una preparación, no olvidemos que en el actual ambiente de masificación se producen accidentes, a veces mortales, por desconocimiento de un medio que, pese a lo que algunos creen no se domina por haber leído un par de artículos y una guía de itinerarios. Pero, sobre todo, de forma institucional hay que ocuparse del asunto a fondo y tomar esas medidas impopulares, que suponen limitar y en ocasiones impedir accesos, obligar a respeter las normas y no dejarse llevar por un entusiasmo, no exento, en ocasiones, de intenciones subterráneas, por «promocionar» espacios como el de la Sierra. No se puede ignorar que la mayoría de las pequeñas consecuencias de un inocente paseo por la montaña de un senderista, la marcha de un montañero o una familia de pic-nic son totalmente inócuas cuando son realizadas por una pequeña población, pero cambian de forma radical cuando se llevan a cabo por miles de personas. La tragedia de la Sierra de Madrid es tener tan cerca el foco urbano de cerca de cinco millones de habitantes y una serie de personas agresivas, emprendedoras, que llevadas de su entusiasmo olvidan las dimensiones de su querida Sierra y la ven y la quieren tratar como si fuera una cadena montañosa del tamaño cuando menos de los Alpes. No lo es y no puede soportar la presión que esto supone.

Exigimos el derecho de las generaciones venideras a heredar lo que se nos dió a nosotros y por ello sólo pedimos algo que parece muy simple: poner sentido común en la utilización de la naturaleza, para ello nos parece esencial convencer a la sociedad y desde luego a las autoridades, que pueden tomar medidas idóneas, del enorme valor que tiene conservar los bosques, que estén vivos y sanos y que en esta conservación es 
muy perjudicial el exceso de presión demográfica que contribuye a acelerar la erosión y la contaminación y tanto más cuanto que de forma indirecta genera el desarrollo de nuevas infraestructuras para atender deseos y necesidades variadas, en una espiral dificil de frenar. Cualquier espacio, y también los naturales, tienen una determinada capacidad óptima, sobrepasar sus límites conduce a su destrucción. 